\title{
Processos de inclusão e educação do campo: Desafios da educação básica no contexto das novas tecnologias
}

\begin{abstract}
Resumo: A educação tem se orientado pelo conceito, ainda que impreciso, de democracia. O reconhecimento da diversidade resultante de elementos econômicos, políticos, sociais e culturais tem motivado a sociedade a exigir projetos políticos-pedagógicos que atendam a diferentes expectativas e necessidades. Nesse sentido, é fundamental compreender a educação inclusiva, suas modalidades, suas características e seus principais desafios. O problema que orienta o presente artigo diz respeito às perspectivas de inclusão na educação do campo. Para tanto, é abordado o ideal de inclusão na educação básica, a educação do campo como direito e, por fim, os desafios e impasses da educação do campo na atualidade, especialmente no contexto das Tecnologias da Informação e Comunicação (TICs). A pesquisa se ampara em estudos, legislações e experiências de educação do campo e apresenta uma análise de conteúdo de publicações científicas recentes sobre os desafios escolares da educação do campo, de modo a identificar discursos e ações que podem ser mobilizados na elaboração de novos projetos de ensino e aprendizagem. Os principais resultados encontrados dizem respeito aos desenvolvimentos importantes de legislações e estudos sobre o tema, ainda que em número reduzido se considerados os desafios a serem superados. Ademais, relatos de experiência compartilham do entendimento de que não é suficiente por si só incorporar novas tecnologias na educação do campo. É necessário pensar também em suas utilidades e potenciais para o ensino e aprendizagem daquele contexto, articulando as novas tecnologias da informação e comunicação à realidade dos alunos de modo a transformar a própria escola.
\end{abstract}

Palavras-chave: educação inclusiva; educação para a diversidade; educação do campo; acesso à tecnologia; tecnologias da informação e comunicação (TICs).

\section{Introdução}

Pesquisas e debates recentes do campo educacional têm se amparado em conceitos e princípios democráticos. Parte-se do reconhecimento de que a escola não pode se isolar do seu contexto social, incentivando reflexões sobre identidade, diversidade e inclusão. Esse reconhecimento - ainda que consolidado mais no discurso do que na prática - deve orientar a formulação de materiais, métodos e processos voltados ao atendimento das expectativas e necessidades dos estudantes, a partir do que há de comum e o que há de específico entre eles.

Objetivando abordar a democratização do espaço escolar, o presente artigo tem como problemática central as perspectivas de inclusão na educação do campo. Para tanto, parte-se de três frentes de discussão: 1. modalidades e ideais de inclusão na Educação
Melina Mörschbächer Instituto Federal de Educação Ciência e Tecnologia Farroupilha (IFFAR)

melina.morschbacher@gmail.com Deyse Reis

Instituto Federal de Educação Ciência e Tecnologia de Minas Gerais (IFMG)

deysereis.reis@gmail.com 
(1) A pandemia da covid-19 também nomeada pandemia do coronavírus, está em curso no período de escrita desse artigo.

Trata-se de uma doença respiratória aguda, identificada pela primeira vez em Wuhan na China, mas que em seguida atingiu proporções globais, sendo reconhecida pela Organização Mundial da Saúde

(OMS). A pandemia impactou

o estilo de vida das pessoas, a circulação entre países e, especificamente na educação, suspendeu aulas presenciais por longos períodos. Desse modo, as TICs assumiram certa centralidade no debate educacional, objetivando a não interrupção de processos de ensino e aprendizagem.
Básica; 2. educação do campo como direito; e 3. desafios e impasses da educação do campo na atualidade, especialmente no contexto das Tecnologias da Informações e Comunicação (TICs).

As motivações para o estudo surgiram a partir da experiência prática da docência no espaço rural, intensificadas por um contexto em que a inclusão é pauta central na elaboração de estratégias de ensino e aprendizagem, ou seja, o contexto de pandemia da covid-191. A educação do campo é uma dentre as modalidades de educação que se constrói com a proposta de garantir o direito constitucional a uma educação gratuita e de qualidade para todos. (BRASIL, 1988) Ela se caracteriza como uma educação pensada para populações do campo, que incluem agricultores familiares, extrativistas, pescadores artesanais, ribeirinhos, assentados e acampados da reforma agrária, trabalhadores assalariados rurais, quilombolas, caiçaras, povos da floresta, caboclos e outros que produzam suas condições materiais de existência a partir do trabalho no meio rural. (BRASIL, 2010)

Segundo Caldart (2011, p. 110), "[...] uma escola do campo não é, afinal, um tipo diferente de escola, mas sim é a escola reconhecendo e ajudando a fortalecer os povos do campo como sujeitos sociais". Desse modo, a educação do campo se propõe a contribuir com o processo de humanização da sociedade como um todo ao respeitar suas lutas, história e saberes, constituindo assim características e desafios específicos que devem ser demarcados.

Neste sentido, os seguintes questionamentos orientaram a escrita do artigo: quais as modalidades e ideais de inclusão escolar? O que é educação do campo? Quais os principais desafios e impasses da educação do campo? De que modo as TICs impactam essa modalidade de educação? Por conseguinte, tais questionamentos motivaram a busca por pesquisas que têm se dedicado a essas temáticas e que têm compartilhado relatos, dados e orientações para o fortalecimento da educação do campo e a identificação e proposição de práticas pedagógicas que visem a acessibilidade e plena participação de todos os alunos.

\section{Modalidades e ideais de inclusão escolar}

A busca contínua pela democracia encontra adversidades e desafios. Se nos séculos passados os debates se centraram no estabelecimento de, ao menos conceitualmente, uma ideia de igualdade pautada na universalidade dos sujeitos, agora compreende-se que 
tal busca deve considerar também suas particularidades. Portanto, tornam-se centrais na agenda das grandes problemáticas a serem estudadas pelos cientistas sociais a diversidade e a inclusão, que se expressam em diferentes ambientes e sob diferentes aspectos, tais como econômico, político, social e cultural.

Nesse sentido, um dos caminhos possíveis para a compreensão e a efetivação desses conceitos é a educação, em especial a que acontece nas escolas regulares. Sendo assim, para compreender de que modo a educação pode protagonizar a consolidação de princípios de equidade que são, inclusive, a base da democracia contemporânea, é fundamental abordar o que representam hoje a educação e o ambiente escolar.

As instituições de ensino escolares possuem um efetivo papel de socialização na vida dos seus alunos, influenciando de forma significativa as suas trajetórias individuais. O sociólogo Pierre Bourdieu (2015, 2011), afirma que há uma perpetuação de valores dentro dos sistemas de ensino tradicionais. Essa se dá a partir do "reforço" de conhecimentos e atitudes determinados que, em geral, também são característicos de determinados grupos ou classe social. Desse modo, os obstáculos e desafios escolares são distribuídos de forma desigual entre os alunos.

Esse argumento é reforçado ainda pelos estudos de Bernard Lahire (1997), especialmente em sua obra Sucesso escolar nos meios populares: as razões do improvável. O autor demonstra que apesar do reconhecido processo de democratização do acesso à escola, as experiências contextuais e individuais dos alunos moldam as suas trajetórias escolares e, posteriormente, profissionais.

Ademais, as escolas ainda estão em processo de superação do paradigma que ficou conhecido como educação tradicional. Essa forma de educar e organizar a vida escolar - que ainda é utilizada em muitas instituições escolares no Brasil e no mundo - tem como base uma estrutura organizacional vertical e padronizada que, por vezes, ainda convive com as heranças de um Estado clientelista e patrimonial amparado em uma concepção de educação gerencialista voltada a processos de avaliação de larga escala. (VIEIRA; VIDAL, 2015)

O educador e patrono da educação brasileira Paulo Freire (1998, 2001, 2011) foi um dos responsáveis por incentivar e disseminar um novo olhar sobre a educação, apoiado na criticidade e na emancipação dos alunos. Ele critica a escola tradicional - um 
(2) A pandemia da covid-19, também nomeada pandemia do coronavírus, está em curso no período de escrita desse artigo.

Trata-se de uma doença respiratória aguda, identificada pela primeira vez em Wuhan na China, mas que em seguida atingiu proporções globais, sendo reconhecida pela Organização Mundial da Saúde (OMS). A pandemia impactou o estilo de vida das pessoas, a circulação entre países e, especificamente na educação, suspendeu aulas presenciais por longos períodos. Desse modo, as TICs assumiram certa centralidade no debate educacional, objetivando a não interrupção de processos de ensino e aprendizagem. modelo bancário e tecnicista, nas palavras do autor - e defende uma educação que possibilite que os alunos construam seus próprios caminhos com autonomia e protagonismo. Para Freire, o fundamento da educação está no entendimento de que o aluno compreende um conteúdo e assimila conhecimentos por meio de uma prática dialética com a sua realidade.

Tais teorias e reflexões, somadas aos resultados da formação dos alunos, sua falta de interesse e motivação e o claro cenário de exclusão, cada vez mais têm incentivado pesquisadores da área da educação na busca de novos modelos, que incentivem o diálogo e a horizontalidade das relações no espaço escolar, dentro e fora de sala de aula. Sendo assim, passou-se a repensar a constituição da instituição escolar como um todo. São incentivadas iniciativas de reflexão sobre identidade, diversidade e inclusão. Segundo Mantoan (2004, p. 7-8), "[...] há diferenças e há igualdades, e nem tudo deve ser igual nem tudo deve ser diferente, [...] é preciso que tenhamos o direito de ser diferentes quando a igualdade nos descaracteriza e o direito de ser iguais quando a diferença nos inferioriza". Porém, por mais que esse seja o discurso e o eixo da maioria dos Projetos Político Pedagógicos das escolas, a efetivação prática de tais iniciativas ainda é um desafio.

A Constituição brasileira apresenta o acesso à educação como um direito fundamental, integrando os reconhecidos direitos sociais de todos os cidadãos. Assim, o Estado tem como responsabilidade assegurar que todos tenham acesso a uma educação pública e de qualidade. Consta no artigo 205 que "[...] a educação, direito de todos e dever do Estado e da família, será promovida e incentivada com a colaboração da sociedade, visando ao pleno desenvolvimento da pessoa, seu preparo para o exercício da cidadania e sua qualificação para o trabalho". (BRASIL, 1988) Além da Constituição, outras normas que regulamentam a educação brasileira ${ }^{2}$ têm pautado e orientado caminhos e mecanismos para a efetivação desse direito, tais como o Estatuto da Criança e do Adolescente (ECA), Lei Federal nº 8.069 de 1990, a Lei de Diretrizes e Bases da Educação (LDBE), Lei Federal no 9.394 de 1996 e outras legislações específicas como o Estatuto da Pessoa com Deficiência, Lei Federal n 13.146 de 2015.

O ECA afirma, em seu artigo 5, que "nenhuma criança ou adolescente será objeto de qualquer forma de negligência, discriminação, exploração, violência, crueldade e opressão, punido na forma da lei qualquer atentado, por ação ou omissão, aos seus 
direitos fundamentais". Em uma perspectiva de inclusão, a legislação brasileira ainda prevê diferentes modalidades de ensino. Essas buscam dar conta das diferentes expectativas e necessidades dos alunos no ambiente escolar. No Quadro 1 são destacadas algumas destas modalidades, com a ressalva de que há muitas outras em debate no Brasil ${ }^{3}$.

Quadro 1 - Universidades com doutorado na Colômbia e as teses encontrada

\begin{tabular}{|c|c|}
\hline MODALIDADE & PERSPECTIVA DE INCLUSÃO \\
\hline EDUCAÇÃO ESPECIAL & $\begin{array}{l}\text { Modalidade de educação voltada } \\
\text { para o atendimento e educação de } \\
\text { pessoas com alguma deficiência, } \\
\text { preferencialmente em instituições de } \\
\text { ensino regulares ou ambientes espe- } \\
\text { cializados. }\end{array}$ \\
\hline EDUCAÇÃO DE JOVENS E ADULTOS [EJA] & $\begin{array}{l}\text { Modalidade de educação caracteriza- } \\
\text { da pela democratização do ensino a } \\
\text { jovens, adultos e idosos que não tive- } \\
\text { ram acesso à educação na escola re- } \\
\text { gular na idade apropriada, permitindo } \\
\text { a retomada dos estudos, consideran- } \\
\text { do sua posição e busca de oportuni- } \\
\text { dades no mercado de trabalho }\end{array}$ \\
\hline EDUCAÇÃO DO CAMPO & $\begin{array}{l}\text { Modalidade de educação que ob- } \\
\text { jetiva superar as desigualdades } \\
\text { históricas constituídas entre campo e } \\
\text { cidade. Trata-se de um projeto volta- } \\
\text { do ao sujeito do campo, articulando } \\
\text { e integrando a educação aos seus } \\
\text { modos de viver e produzir, respei- } \\
\text { tando suas temporalidades e sua } \\
\text { relação com a natureza. Considera } \\
\text { as peculiaridades da vida no campo } \\
\text { e de cada região, orientando-se pelo } \\
\text { desenvolvimento de conteúdos e } \\
\text { metodologias apropriadas às suas } \\
\text { necessidades e interesses }\end{array}$ \\
\hline EDUCAÇÃO INDÍGENA & $\begin{array}{l}\text { Modalidade de educação caracteriza- } \\
\text { da pelo respeito às especificidades } \\
\text { étnico-culturais de cada comunidade } \\
\text { indígena, desenvolvendo-se uma } \\
\text { educação escolar específica, dife- } \\
\text { renciada, intercultural e bilíngue/ } \\
\text { multilíngue. }\end{array}$ \\
\hline
\end{tabular}

(3) Outras modalidades que têm sido pauta em debates sobre inclusão são, por exemplo, a educação para a população em situação de rua e a educação ambiental. 


\begin{tabular}{|l|l|}
\hline EDUCAÇÃO QUILOMBOLA & $\begin{array}{l}\text { Modalidade de educação caracteriza- } \\
\text { da pelo respeito às especificidades } \\
\text { étnico-culturais de cada comunidade } \\
\text { quilombola, desenvolvendo-se em } \\
\text { unidades educacionais inscritas em } \\
\text { suas terras e cultura com proposta } \\
\text { pedagógica própria. }\end{array}$ \\
\hline EDUCAÇÃO À DISTÂNCIA & $\begin{array}{l}\text { Modalidade de educação caracteri- } \\
\text { zada pela mediação por tecnologias. } \\
\text { Nela, docentes e discentes estão } \\
\text { separados espacial e/ou temporal- } \\
\text { mente. }\end{array}$ \\
\hline
\end{tabular}

Fonte: elaboração das autoras.

Todas essas modalidades são resultantes de embates e lutas históricas sobre reconhecimento e igualdade e resultam de um longo processo de mudança. A desigualdade e a exclusão sempre estiveram presentes na história da educação e reconhecê-las muitas vezes exige não apenas a mensuração de dados socioeconômicos, mas também o reconhecimento da reprodução de relações de dominação simbólicas, conforme assinala o sociólogo Pierre Bourdieu (2015). Existem vários estigmas associados às diferenças, assim, além de barreiras objetivas é preciso atentar-se às barreiras que colocam estigmas de "incapacidade", "desajuste" e "anormalidade".

No caso específico da educação do campo o estigma se consolidou a partir do antagonismo entre campo e cidade, pautando a realidade do primeiro às necessidades e moldes do segundo. (MINISTERIO DA EDUCAÇÃO, 2002) Contudo, nos últimos anos, movimentos sociais têm se articulado e protagonizado a reivindicação por espaços próprios, questionando os modelos postos e apresentando alternativas às tradicionais escolas rurais e à tradicional formação de professores. (MOLINA; FREITAS, 2011)

\section{A educação do campo como direito}

Refletir sobre a educação do campo é refletir sobre inclusão, na medida em que o projeto da escola é pensado para os sujeitos do campo, articulando e integrando as práticas educativas às práticas sociais, culturais e de desenvolvimento desse espaço. (CALDART, 2011) Nesse sentido, é necessária a desconstrução de preconceitos para superar as desigualdades educacionais, historicamente constituídas entre campo e cidade. 
A educação do campo não pode ser pensada no sentido de atender demandas das áreas urbanas; e também não é mais possível pensar em uma escola que transfira um modelo didático pedagógico pensado para da cidade para o campo. Rompe-se o antagonismo campo e cidade na sua lógica hierárquica e passa-se pensar em diversidade e complementaridade, respeitando assim temporalidades e diferenças no modo de ser, viver e produzir, especialmente no que diz respeito à relação com a natureza. Segundo Arroyo, Caldart e Molina (2011, p. 15),

Esta visão do campo como um espaço que tem suas particularidades e que é ao mesmo tempo um campo de possibilidades de relação dos seres humanos com a produção das condições de existência social, confere à Educação do Campo o papel de fomentar reflexões sobre um novo projeto de desenvolvimento e o papel do campo neste projeto. Também o papel de fortalecer a identidade e a autonomia das populações do campo e ajudar o povo brasileiro a compreender que não há uma hierarquia, mas uma complementaridade: a cidade não vive sem campo que não vive sem cidade.

Ademais, não se pode esquecer que a realidade da desigualdade do campo se articula com outros marcadores econômicos, políticos, sociais e culturais. Segundo Wanderley (2000) as situações de injustiça e desigualdade se destacam em pelo menos três outras realidades: a indígena, a negra e a feminina, visto que entre os segmentos sociais rurais, estas parcelas se encontram em situação de maior vulnerabilidade, exploração e exclusão.

Nesse sentido, a escola assume um papel central, visto que, como mencionado, é um dos principais agentes de socialização dos sujeitos, produzindo e reproduzindo conhecimento ao longo do tempo. Ainda, na realidade rural, a escola representa por vezes espaço de resistência, quando estabelece espaço para a cultura e as identidades de seus territórios. (ARROYO; CALDART; MOLINA, 2011)

O desenvolvimento de uma perspectiva de escola do campo, dessa forma, não pode ser pensado de forma desvinculada dos movimentos sociais e das lutas dos Sem Terra, que reivindicaram a implantação de escolas públicas em áreas de Reforma Agrária. Para Caldart (2008, p. 71-72), 
A Educação do Campo nasceu tomando/precisando tomar posição no confronto de projetos de campo: contra a lógica do campo como lugar de negócio, que expulsa as famílias, que não precisa de educação nem de escolas porque precisa cada vez menos de gente, a afirmação da lógica da produção para a sustentação da vida em suas diferentes dimensões, necessidades, formas. E ao nascer lutando por direitos coletivos que dizem respeito à esfera do público, nasceu afirmando que não se trata de qualquer política pública: o debate é de forma, conteúdo e sujeitos envolvidos.

É nesse sentido, especialmente, que se demarca a diferença entre educação do campo e educação rural. Segundo Simões e Torres (2011) a primeira tem registros no Brasil pelo menos desde 1889, com a Proclamação da República, visando resolver problemas para o dito desenvolvimento do país, tais como a alta taxa de analfabetismo. Nesse caso, pensava-se em um modelo único para atender cidade e campo, pautando-se prioritariamente pela primeira.

Na década de 1980, entretanto, coletivos e movimentos sociais organizados constituíram novas formas de se pensar a escola, o ensino e a aprendizagem, garantindo assim um ideal de educação do campo, que serve as expectativas e necessidades do campo. (SIMÕES; TORRES, 2011) Após a afirmação de uma educação como direito de todos na Constituição Federal (BRASIL, 1988), a Lei de Diretrizes e Bases da Educação, em seu artigo 28, passa a reconhecer e orientar a educação em áreas rurais, representando um avanço na legislação sobre o tema:

\footnotetext{
Na oferta de educação básica para a população rural, os sistemas de ensino promoverão as adaptações necessárias à sua adequação às peculiaridades da vida rural e de cada região, especialmente: I - conteúdos curriculares e metodologias apropriadas às reais necessidades e interesses dos alunos da zona rural; II - organização escolar própria, incluindo adequação do calendário escolar às fases do ciclo agrícola e às condições climáticas III - adequação à natureza do trabalho na zona rural
}

O documento, mesmo representando um avanço deixou lacunas quanto a diversas questões, tais como a participação da comunidade e didáticas pedagógicas específicas. (LEITE, 1999) Essas, entretanto, vêm sendo abordadas, discutidas e desenvolvidas em ambientes escolares e por meio de leis e pareceres específicos. No Quadro 2 são apresentados alguns dos marcos legais importantes sobre a educação do campo no Brasil. 
Quadro 2 - TMarcos Legais sobre a Educação do Campo no Brasil

\begin{tabular}{|c|c|c|}
\hline ANO & DOCUMENTO & CONTEÚDO \\
\hline 1988 & Constituição Federal de 1988 & $\begin{array}{l}\text { Estabelece em seu artigo } 205 \\
\text { que a educação é um direito } \\
\text { de todos e dever do Estado e } \\
\text { da família }\end{array}$ \\
\hline 1990 & $\begin{array}{l}\text { Estatuto da Criança e do Adoles- } \\
\text { cente - Lei } \mathrm{n}^{\circ} 8069 / 90\end{array}$ & $\begin{array}{l}\text { Estabelece em seu artigo } 53 \\
\text { que a criança e o adolescente } \\
\text { têm o direito ao acesso à es- } \\
\text { cola pública e gratuita próxima } \\
\text { de sua residência. Tal preceito } \\
\text { também deve ser assegurado } \\
\text { aos alunos do campo. }\end{array}$ \\
\hline 1996 & $\begin{array}{l}\text { Lei de Diretrizes e Bases da Edu- } \\
\text { cação (LDB) - Lei nº 9394/96 }\end{array}$ & $\begin{array}{l}\text { Estabelece em seu artigo } 28 \\
\text { que na oferta de educação bá- } \\
\text { sica para a população rural, os } \\
\text { sistemas de ensino promove- } \\
\text { rão as adaptações necessárias } \\
\text { à sua adequação às peculiari- } \\
\text { dades da vida rural e de cada } \\
\text { região }\end{array}$ \\
\hline 2002 & $\begin{array}{c}\text { Diretrizes Operacionais para } \\
\text { Educação Básica nas Escolas do } \\
\text { Campo - Resolução CNE/CEB } \\
n^{\circ} 01 / 02\end{array}$ & $\begin{array}{l}\text { Estabelece em seu artigo } 1^{\circ} \\
\text { que a resolução institui as } \\
\text { Diretrizes Operacionais para a } \\
\text { Educação Básica nas escolas } \\
\text { do campo a serem observadas } \\
\text { nos projetos das instituições } \\
\text { que integram os diversos siste- } \\
\text { mas de ensino. }\end{array}$ \\
\hline 2010 & $\begin{array}{c}\text { Política de Educação do Campo } \\
\text { e o Programa Nacional de Educa- } \\
\text { ção na Reforma Agrária, Pronera } \\
\text { - Decreto } \mathrm{n}^{\circ} 7352 / 10\end{array}$ & $\begin{array}{l}\text { Estabelece em seu artigo } 1^{\circ} \\
\text { que a União tem o dever legal } \\
\text { de ampliar a política da educa- } \\
\text { ção do campo, sendo que os } \\
\text { Estados, Municípios e Distrito } \\
\text { Federal colaborarão com o de- } \\
\text { senvolvimento dessa política; e } \\
\text { determina a oferta de formação } \\
\text { inicial e continuada de pro- } \\
\text { fissionais da educação, bem } \\
\text { como estabelece a garantia de } \\
\text { dar condições de infraestrutura } \\
\text { e transporte escolar para a po- } \\
\text { pulação camponesa. }\end{array}$ \\
\hline
\end{tabular}

Fonte: elaboração das autores. 
(4) Sobre a pedagogia da alternância, Jesus (2010, p. 10) afirma que "a formação na alternância tem como objetivo principal possibilitar a educação em tempo integral, envolver as famílias na educação dos filhos, fortalecer a prática do diálogo entre os diferentes atores que participam dos processos de formação dos educandos. Além de proporcionar qualificação técnica (técnico em agropecuária) aos estudantes camponeses/as com o intuito de fortalecer a agricultura camponesa - estudar e continuar no campo, contribuir nos trabalhos da propriedade familiar, desenvolver alternativas de permanência na terra, dessa forma, diminuir a migração campo/cidade".
Em relação ao Decreto de 2010, ainda é importante mencionar que várias questões são abordadas, tais como a valorização da cultura e das tradições da população rural e a pedagogia da alternância ${ }^{4}$. Ademais, o documento em seu artigo $2^{\circ}$ estabelece cinco princípios para a educação do campo:

I - respeito à diversidade do campo em seus aspectos sociais, culturais, ambientais, políticos, econômicos, de gênero, geracional e de raça e etnia;II - incentivo à formulação de projetos político-pedagógicos específicos para as escolas do campo, estimulando o desenvolvimento das unidades escolares como espaços públicos de investigação e articulação de experiências e estudos direcionados para o desenvolvimento social, economicamente justo e ambientalmente sustentável, em articulação com o mundo do trabalho; III - desenvolvimento de políticas de formação de profissionais da educação para o atendimento da especificidade das escolas do campo, considerando-se as condições concretas da produção e reprodução social da vida no campo; IV - valorização da identidade da escola do campo por meio de projetos pedagógicos com conteúdos curriculares e metodologias adequadas às reais necessidades dos alunos do campo, bem como flexibilidade na organização escolar, incluindo adequação do calendário escolar às fases do ciclo agrícola e às condições climáticas; $\mathrm{V}$ - controle social da qualidade da educação escolar, mediante a efetiva participação da comunidade e dos movimentos sociais do campo. (BRASIL, 2010)

Tais princípios têm como base um ideal de educação que valoriza a diversidade e o respeito aos sujeitos. Por essa razão, grande parte da literatura sobre educação do campo se utiliza das experiências e formulações teóricas de Paulo Freire, que se dedicou em sua obra ao cenário brasileiro, buscando a superação de realidades de exclusão e encontrando na educação um de seus principais caminhos.

No livro Pedagogia da autonomia: saberes necessários à prática educativa (2011), o autor aborda práticas pedagógicas que objetivam a autonomização dos alunos, sempre respeitando os seus conhecimentos prévios. Para tanto, é necessário que o professor compreenda o aluno como sujeito social e histórico, entendendo de forma ampla o "ato de formar". Essa formação deve ser ética e cidadã, promovendo reflexões críticas do sujeito sobre a sua própria realidade. Assim, evidencia-se que a educação não pode ser 
separada do mundo da política e do engajamento para a ação. Nas palavras de Paulo Freire (1998, p. 30),

Não existe tal coisa como um processo de educação neutra. Educação ou funciona como um instrumento que é usado para facilitar a integração das gerações na lógica do atual sistema e trazer conformidade com ele, ou ela se torna a 'prática da liberdade'o meio pelo qual homens e mulheres lidam de forma crítica com a realidade e descobrem como participar na transformação do seu mundo.

\section{Os desafios da educação do campo no contexto das tecnologias da informação e comunicação}

A educação brasileira tem muitos desafios a serem enfrentados, especialmente no que se refere à inclusão e à igualdade de condições de ensino e aprendizagem. A educação do campo é uma dentre as modalidades de educação que se constrói com a proposta de garantir o direito constitucional a uma educação gratuita e de qualidade para os alunos que residem no ambiente rural. Apesar da formação de um debate consistente e da criação de legislações específicas, é reconhecido que existem diversas problemáticas que impedem o atendimento das expectativas e necessidades desses alunos e territórios.

Dentre os reconhecidos desafios da educação do campo destacam-se os altos índices de analfabetismo, a falta e fechamento de escolas, a estrutura precária, a ausência de políticas de qualificação de professores e a existência de currículos distanciados das reais necessidades locais. (MOLINA; FREITAS, 2011) Essas problemáticas compartilhadas por escolas em zonas rurais ainda se somam a problemáticas específicas das distintas realidades do Brasil, que englobam, como já mencionado, agricultores familiares, extrativistas, pescadores artesanais, ribeirinhos, assentados e acampados da reforma agrária, trabalhadores assalariados rurais, quilombolas, caiçaras, povos da floresta, caboclos, dentre outros. (BRASIL, 2002)

A despeito da importância de todos esses debates, destaco nesse artigo duas questões prementes que aparecem como desafios à educação do campo, especialmente no ano de 2020. Por um lado, reconhece-se a emergência de uma nova realidade global e digital, 
(5) A Revista Brasileira de Educação do Campo (RBEC) é uma publicação do Departamento

de Educação do Campo, Curso de Licenciatura em Educação do Campo, da Universidade Federal do Tocantins. Ela possui fluxo contínuo e reúne pesquisas sobre distintas áreas, tais como: História da Educação do Campo; Movimentos Sociais; Políticas Públicas; Povos Indígenas e Educação; Formação Docente; Jovens e Adultos do Campo; Didática e Práticas Pedagógicas em Artes e Música; Arte na Educação do Campo; Interculturalidade na Educação do Campo; Pedagogia da Alternância; Questão Agrária e Campesinato. Disponível em: https://sistemas.uft. edu.br/periodicos/index.php/campo/ index. Acesso em: 20 maio 2021. que se impõe a cada dia. Por outro, vivencia-se o momento histórico de uma pandemia em escala mundial, a covid-19.

A nova realidade global e digital - por vezes inclusiva, por outras excludente - nos traz problemáticas que dizem respeito à relação da sociedade com as novas tecnologias digitais. (CASTELLS, 2008; GIDDENS, 2000; LÉVY, 2000) Tais problemáticas também impactam diretamente as escolas, de modo que surgem debates sobre as TICs aplicadas à educação e modalidades de educação a distância. Ao mesmo tempo, discutem-se letramento digital, desigualdade de acesso à internet e mesmo a oferta de uma formação continuada para os próprios professores e servidores técnicos do espaço rural. Quando voltamos nosso olhar para a utilização das TICs, percebemos que muitos são os avanços necessários para que os alunos do campo tenham um acesso compatível com o seu contexto e necessidades.

A covid-19 vem ao encontro desses debates, evidenciando a desigualdade e a falta de um planejamento nacional para a inclusão digital em um contexto no qual o distanciamento social é necessário. Ademais, as distâncias em áreas rurais se impuseram de forma ainda mais significativa, impedindo a realização de outras estratégias utilizadas em várias cidades do país, tais como a disponibilização e entrega de materiais e atividades impressas, o que por si só já promove a desigualdade de condições de ensino e aprendizagem.

A partir dessas reflexões foi realizada uma pesquisa de caráter bibliográfico levantando os artigos publicados nos últimos anos sobre esses temas na base de dados do Scielo, relacionando "educação do campo" às seguintes palavras-chave: "Tecnologias", "Tecnologias da Informação e Comunicação", "TICs" e "Inclusão Digital". Entretanto, apesar de os resultados indicarem um aumento de pesquisas relacionadas ao uso de tecnologias na educação do campo, os artigos ainda se apresentam em um número bastante reduzido e o acesso ao resumo demonstrou uma abordagem tangencial sobre os temas aqui selecionados.

Desse modo, foi selecionada uma segunda fonte de buscas, a Revista Brasileira de Educação do Campo (RBEC) $)^{5}$, especializada em pesquisas de temas vinculados à educação do campo. Esta apresentou nos últimos anos pesquisas interessantes sobre os desafios da educação do campo no contexto das TICs, Elas abordam as concepções dos estudantes do campo sobre tecnologias (BIERHALZ; MEDEIROS DA FONSECA; DE VARGAS OLIVA, 2019); o uso das 
TICs por estudantes do Ensino Médio (LUZ; SANTOS; SANTOS, 2019); o uso didático de softwares educacionais e aplicativos em dispositivos móveis (SANTOS; LEÃO, 2017); as implicações das novas tecnologias para a aprendizagem e o desenvolvimento humano (BERSI; MIGUEL; ARENA, 2019); o ativismo e diálogo nas mídias digitais (VENANCIO, 2016); a produção científica sobre a presença da tecnologia na educação do campo (SOUZA; PEREIRA; MACHADO, 2018) e, nesse cenário particular, os desafios no contexto da pandemia da covid-19 e a adoção do ensino remoto nas escolas. (ESTRADA-ARAOZ et al., 2020; NENKO; KTBALNA; SNISARENKO, 2020; NOVAIS BRITO; SANTANA; FERNANDES, 2020)

A maioria das pesquisas identificadas optou pela coleta de dados qualitativos por meio de estudos de caso, dedicando-se ao estudo de realidades específicas de escolas localizadas em zonas rurais. Isto indica a importância de considerar a multiplicidade de experiências e desafios da educação do campo, especialmente no que diz respeito às TICs. Essa multiplicidade, destaca-se, não ocorre apenas devido à dificuldade de acesso decorrentes da não democratização dos equipamentos ou conectividade, mas também à distância de sentido dessas tecnologias no contexto rural, resultando, por vezes, no desinteresse e na apatia por parte dos alunos. (ESTRADA-ARAOZ et al., 2020)

As TICs apresentam uma ampla gama de possibilidades. Dentre atividades síncronas e assíncronas, podem ser mencionadas videoaulas, videoconferências, chats, fóruns e bibliotecas virtuais. Ademais, existem plataformas que auxiliam professores e alunos no processo de ensino e aprendizagem, dinamizando e "gamificando" ${ }^{6}$ atividades avaliativas e de acompanhamento. Ainda assim, essas ferramentas e estratégias precisam ser dotadas de sentido e esse sentido se constitui por meio da orientação docente, mas também por meio da relação com o contexto social da comunidade escolar.

A educação mediada por tecnologias, associada muitas vezes à inclusão, flexibilização, dinamismo, autonomia e interatividade, pode representar o oposto desses objetivos se adotada em um contexto hostil. Esse tem sido majoritariamente o contexto do ensino remoto adotado a partir do desencadeamento da pandemia da covid-19 no Brasil, no qual escolas e planejamentos didáticos previamente estabelecidos precisaram se adaptar em poucas semanas a um ensino remoto que, como já destacado, não se confunde com a proposta de uma educação a distância. A educação passa a conviver
(6) A gamificação da educação têm sido uma prática cada vez mais adotada em processos de ensino e aprendizagem, especialmente no contexto digital. Trata-se da adoção da lógica e do design de jogos no contexto escolar com o objetivo de despertar o interesse dos alunos. 
com novos problemas sanitários, aumento do desemprego e das desigualdades sociais e dificuldade de acesso a serviços públicos de qualidade, além de um cenário de incerteza e insegurança, com impactos também a nível de saúde mental.

Novais Brito, Santana e Fernandes (2020), ao analisar e refletir sobre a educação do campo no contexto da covid-19 em um município do interior da Bahia, concluem que se por um lado o ensino remoto se apresenta como uma possibilidade de vínculo, aproximação da família com a escola e, especialmente, de continuidade das atividades de ensino e aprendizagem, por outro lado expõe a não democratização de uma educação de qualidade para todos. O uso de tecnologias digitais na educação do campo exige um processo planejado de disponibilização de recursos materiais e humanos, suporte técnico, formação continuada de professores, assistência aos alunos e suas famílias e espaços adequados para discussão, formulação e reflexão sobre processos de ensino e aprendizagem possíveis e necessários.

São várias as potencialidades e desafios identificados a partir do uso das novas tecnologias da comunicação e informação no campo da educação. Todavia, as considerações apresentadas por grande parte dos artigos se encontram em um argumento central, o de que não é suficiente incorporar novas tecnologias na educação do campo. É necessário pensar também em suas utilidades e potenciais para o ensino e aprendizagem daquele contexto, articulando as TICs à realidade dos alunos de modo a transformar a própria escola.

\section{Considerações finais}

O presente artigo demonstra que existe um processo de reconhecimento da educação do campo em instituições acadêmicas e políticas, por meio da realização de pesquisas, diagnósticos e legislações específicas. Esse reconhecimento, inserido nos debates sobre democracia e inclusão, entretanto, enfrenta limitações objetivas que carecem de proposições de enfrentamento ou de condições objetivas para a realização das proposições já existentes.

Ademais é importante destacar que o processo de reconhecimento e investimento do setor público em políticas específicas para a educação do campo não se constitui como um processo linear e irreversível, de modo que são necessárias mobilizações e 
vigilância constantes para a garantia e manutenção de direitos já adquiridos pelas escolas e suas comunidades.

Em um novo cenário, demarcado pelos desafios concernentes às TICs, identifica-se que ainda existe uma carência de reflexões e publicações sobre o tema. Ainda assim, as publicações encontradas demonstram caminhos possíveis para uma inserção da tecnologia nas escolas, dotada de um sentido para a educação do campo. Os relatos de experiência compartilham do entendimento de que não é suficiente incorporar tecnologias na educação do campo. É necessário pensar também em suas utilidades e potenciais para o ensino e aprendizagem daquele contexto, articulando as novas tecnologias da informação e comunicação à realidade dos alunos de modo a transformar a própria escola.

\title{
Inclusion Processes And Field Education: Challenges For Primary Education Vis-À-Vis New Technologies
}

\begin{abstract}
Educations has been informed by the useful, although imprecise, concept of democracy. Recognising that the diversity stemming from economic, social, political, and cultural elements has motivated society to demand political-pedagogical projects that address different expectations and needs. Thus, it is paramount to understand inclusive education, its modalities, characteristics, and challenges. The research question that guides this article is concerned with the perspectives of inclusion in field education. As a consequence, I discuss the concept of inclusion in primary education; field education as a right per se; and the challenges and deadlocks in contemporary field education, especially in the context of new Information and Communication Technologies (ICTs). The research is cemented on previous studies, legislation and experiences of field education, and it also presents a content analysis of recent scientific papers on the challenges of field education, aiming to identify discourses and actions that may be mobilised to design new projects of teaching and learning. The main findings reveal that important bills have been recently approved at the national level, yet they are still limited in number and scope to address and overcome the challenges of field education. Furthermore, experience reports share the understanding that incorporating new technologies in field education alone does not suffice: it is also necessary to reflect upon their uses and potentials to teaching and learning in that specific context, articulating, in the process, new information and communication technologies with students' realities, ultimately transforming the school itself.
\end{abstract}

Keywords: teacher knowledge and practices; educational contexts; dissertations in education in Colombia; continuing education. 


\title{
Conocimientos y prácticas docentes en educación continua: análisis de tesis de Colombia
}

\begin{abstract}
Resumen: El artículo presenta una reflexión sobre la importancia de la formación del profesorado para la calificación de los conocimientos y prácticas pedagógicas, además de la construcción de la identidad profesional y el reconocimiento de los discursos docentes, desde los debates propuestos en el ámbito del "Grupo de estudio sobre estudiantes" (Geres). Estudiamos 123 tesis doctorales en instituciones de educación superior en Colombia, defendidas entre 2006 y 2019, en cinco universidades. Al analizar las tesis, observamos un creciente interés en el conocimiento teórico, práctico y experimental de los docentes, así como en la relación que la investigación establece entre el conocimiento y las prácticas docentes en diferentes contextos educativos. De manera similar, podemos ver interés en enfocarnos en las realidades y problemas presentes en la Educación Básica y Superior, considerando estas investigaciones y niveles de enseñanza, un campo propicio para desarrollar propuestas y transformaciones en las políticas educativas en Colombia.
\end{abstract}

Palabras clave: conocimiento y prácticas docentes; contextos educativos; tesis en educación en Colombia; educación continua.

\section{Referências}

ARROYO, M. G.; CALDART, R. S.; MOLINA, M. C. (org.). Por uma educação do campo. Petrópolis: Vozes, 2011. BERSI, R. M.; MIGUEL, J. C.; ARENA, D. As tecnologias digitais de informação e comunicação pelo prisma da linguagem digital. Revista Brasileira de Educação Do Campo, [Tocantinópolis], v. 4, p. 1-16, 2019.

BIERHALZ, C. D. K.; MEDEIROS DA FONSECA, E.; DE VARGAS OLIVA, I. Concepções dos estudantes de uma escola do campo sobre tecnologia. Revista Brasileira de Educação do Campo, [Tocantinópolis], v. 4, p. 1-21, 2019.

BOURDIEU, P. A escola conservadora: as desigualdades frente à escola e à cultura. In: NOGUEIRA, M. A.; CATANI, A. (org.). Pierre Bourdieu: escritos de educação. Petrópolis: Vozes, 2015.

BOURDIEU, P. O poder simbólico. Rio de Janeiro: Bertrand Brasil, 2011.

BRASIL. [Constituição (1988)]. Constituição da República Federativa do Brasil. Brasília, DF: Presidência da Republica, 1988. Disponível em: http://www.planalto.gov.br/ccivil_03/Constituicao/Constituicao.htm. Acesso em: 20 maio 2021.

BRASIL. Lei $n^{\circ}$ 9.394, de 20 de dezembro de 1996. Estabelece as diretrizes e bases da educação nacional. Brasília, DF: Diário Oficial da União, 1996. Disponível em: http://www.planalto.gov.br/ccivil_03/leis/19394. htm. Acesso em: 20 maio 2021.

BRASIL. Lei Federal no 8069, de 13 de jutho de 1990. Dispõe sobre o Estatuto da Criança e do Adolescente e dá outras providências. Brasília, DF: Presidência da República, 1990. Disponível em: http://www. planalto.gov.br/ccivil_03/leis/18069.htm. Acesso em: 20 maio 2021. 
BRASIL. Decreto $n^{\circ}$ 7.352, de 4 de novembro de 2010. Dispõe sobre a política de educação do campo e o Programa Nacional de Educação na Reforma Agrária - Pronera. Brasília, DF: Presidência da República, 2010. Disponível em: http://portal.mec.gov.br/docman/marco-2012pdf/10199-8-decreto-7352-de4-de-novembro-de-2010/file. Acesso em: 20 maio 2021.

BRASIL. Lei $n^{\circ}$ 13.146, de 6 de julho de 2015. Institui a lei brasileira de inclusão da pessoa com deficiência (estatuto da pessoa com deficiência). Brasília, DF: Presidência da República, 2015. Disponível em: http://www.planalto.gov.br/ccivil_03/_ato2015-2018/2015/Lei/ L13146.htm. Acesso em: 20 maio 2021.

CALDART, R. S. A escola do campo em movimento. In: ARROYO, M. G.; CALDART, R. S.; MOLINA, M. C. (org.). Por uma educação do campo. Petrópolis: Vozes, 2011. p. 87-132.

CALDART, R. S. Sobre educação do campo. In: SANTOS, C. A. dos. (org.). Por uma Educação do Campo: campo-políticas públicas-Educação. Brasília, DF: INCRA; MDA, 2008.

CASTELLS, M. A Sociedade em rede. São Paulo: Paz e Terra, 2008. v. 1.

ESTRADA-ARAOZ, E. G. et al. Actitud de los estudiantes universitarios frente a la educación virtual en tiempos de la pandemia de COVID-19. Revista Brasileira de Educação do Campo, Tocantinópolis, v. 5, p. 10237, 8 set. 2020 .

FREIRE, P. Educação como prática da liberdade. Rio de Janeiro: Paz e Terra, 2001.

FREIRE, P. Pedagogia do oprimido. 25. ed. Rio de Janeiro: Paz e Terra, 1998.

FREIRE, P. Pedagogia do oprimido. 25. ed. Rio de Janeiro: Paz e Terra, 1998.

FREIRE, P. Pedagogia da autonomia: saberes necessários à prática educativa. 43. ed. São Paulo: Paz e Terra, 2011.

GIDDENS, A. Mundo em descontrole: o que a globalização está fazendo de nós. 3. ed. Rio de Janeiro: Record, 2000.

JESUS, J. N. de. A pedagogia da alternância e o debate da educação no/ do campo no estado de Goiás. Revista Nera, Presidente Prudente, v. 8, p. 07-20, 2011. Disponível em: http://www.reformaagrariaemdados.org.br/ sites/default/files/1334-3798-1-PB.pdf. Acesso em: 20 maio 2021.

LAHIRE, B. Sucesso escolar nos meios populares: as razões do improvável. São Paulo: Ática, 1997.

LEITE, S. C. Escola rural: urbanização e políticas educacionais. São Paulo: Cortez, 1999.

LÉVY, P. Cibercultura. Lisboa: Instituto Piaget, 2000.

LUZ, F. C. de O. C. A. da; SANTOS, S. A. dos; SANTOS, E. M. dos. Uso das TIC's por educandos do Ensino Médio de escolas do campo. Revista Brasileira de Educação do Campo, [Tocantinópolis], v. 4, p. 01-19, 2019. 
MANTOAN, M. T. E. O direito de ser, sendo diferente, na escola. Revista CEJ, Brasília, n. 26, p. 36-44, 2004. Disponível em: http://www.cjf.jus. br/ojs2/index.php/revcej/article/view/622. Acesso em: 20 maio. 2021.

MINISTERIO DA EDUCAÇÃO. Conselho Nacional de Educação. Parecer CNE/CEB 36/2001 - Homologado. Brasília, DF: Diário Oficial da União, 2001. Disponível em: http://portal.mec.gov.br/index. php?option $=$ com_docman\&view $=$ downloadEalias $=11989-$ pceb036-01pdfEcategory_slug = novembro-2012-pdfEItemid =30192. Acesso em: 20 maio 2021.

MINISTERIO DA EDUCAÇÃO. Resolução CNE/CEB 1 de 01 de abril de 2002. Institui Diretrizes Operacionais para a Educação Básica nas Escolas do Campo. Brasília, DF: Diário Oficial da União, 2002. Disponível em: http://portal.mec.gov.br/index. php? option $=$ com_docman\&view $=$ downloadEalias $=1380$ 0-rceb001-02pdfEItemid = 30192. Acesso em: 20 maio 2021.

MOLINA, M. C.; FREITAS, H. C. de A. Avanços e desafios na construção da Educação do Campo. Revista Em Aberto, Brasília, DF, v. 24, n. 85 , p. 17-31, 2011.

NENKO, Y.; YBALNA, N.; SNISARENKO, Y. The COVID-19 Distance Learning: Insight from Ukrainian students. Revista Brasileira de Educação do Campo, v. 5, p. 8925, 30 abr. 2020.

NOVAIS BRITO, T.; SANTANA, J. DE J.; FERNANDES, M. N. Educação do Campo na conjuntura da pandemia: alcances, impactos e desafios. Revista Brasileira de Educação do Campo, [Tocantinópolis], v. 5, p. e10278, 16 dez. 2020.

SANTOS, S. F.; LEÃO, M. F. Uso de objetos educacionais digitais para ensinar sistemas do corpo humano em uma escola do campo. Revista Brasileira De Educação Do Campo, [Tocantinópolis], v. 2, n. 3, p. 861880, 2017.

SIMÕES, W.; TORRES, M. R. Educação do campo: por uma superação da Educação Rural no Brasil. 2011. TCC (Especialização em Educação do Campo) - Universidade Federal do Paraná, 2011. Disponível em: http:// acervodigital.ufpr.br/bitstream/handle/1884/38662/R\%20-\%20E\%20\%20MIRIAM\%20ROSA\%20TORRES.pdf?sequence =1. Acesso em: 20 maio 2021.

SOUZA, V. V.; PEREIRA, E. C.; MACHADO, C. C. A presença da tecnologia na educação do campo: mapeamento da produção científica nacional dos últimos cinco anos. Revista Brasileira de Educação do Campo, [Tocantinópolis], n. 3, v. 1, p. 245-259, 2018.

VENANCIO, R. D. O. Por uma educomunicação ciberpopular: ativismo e diálogo nas mídias digitais. Revista Brasileira de Educação do Campo, [Tocantinópolis], n. 1, v. 2, p. 550-571, 2016. 
VIEIRA, S. L.; VIDAL, E. M. Gestão democrática da escola no brasil: desafios à implementação de um novo modelo. Revista Iberoamericana de Educación, Araraquara, v. 67, n. 1, p. 9-38, 2015. Disponível em: https://rieoei.org/historico/documentos/rie67a01.pdf. Acesso em: 20 maio 2021.

WANDERLEY, L. E. W. A questão social no contexto da globalização: o caso latino-americano e o caribenho. In: CASTEL, R.; WANDERLEY, L. E.W; BELFIORE-WANDERLEY, M. Desigualdade e a questão social. 2. ed. São Paulo: Educ, 2000. p. 51-161.

Submetido em 30/10/2020.

Aceito em 11/06/2021. 